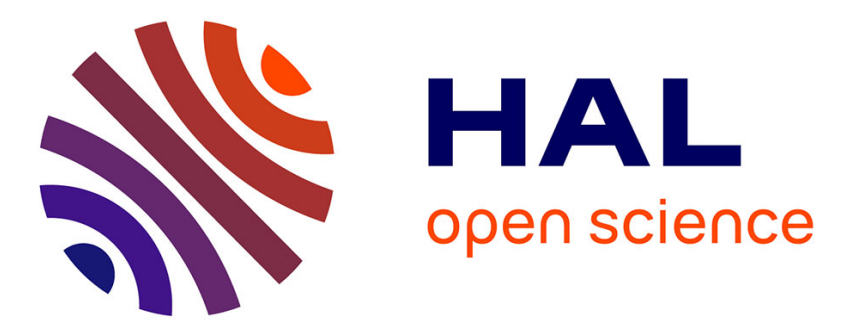

\title{
NO2 gas sensing studies: Impact of geometrical and physical characteristics of ohmic contacts on n-InP epitaxial sensitive layer
}

Laure Berry, J. Brunet, Christelle Varenne, Lionel Mazet, Alain Pauly, Katarzyna Wierzbowska

\section{To cite this version:}

Laure Berry, J. Brunet, Christelle Varenne, Lionel Mazet, Alain Pauly, et al.. NO2 gas sensing studies: Impact of geometrical and physical characteristics of ohmic contacts on n-InP epitaxial sensitive layer. 2006. hal-00091799

\section{HAL Id: hal-00091799 https://hal.science/hal-00091799}

Preprint submitted on 7 Sep 2006

HAL is a multi-disciplinary open access archive for the deposit and dissemination of scientific research documents, whether they are published or not. The documents may come from teaching and research institutions in France or abroad, or from public or private research centers.
L'archive ouverte pluridisciplinaire HAL, est destinée au dépôt et à la diffusion de documents scientifiques de niveau recherche, publiés ou non, émanant des établissements d'enseignement et de recherche français ou étrangers, des laboratoires publics ou privés. 


\title{
$\mathrm{NO}_{2}$ GAS SENSING STUDIES : IMPACT OF GEOMETRICAL AND PHYSICAL CHARACTERISTICS OF OHMIC CONTACTS ON n-InP EPITAXIAL SENSITIVE LAYER
}

\author{
L.Berry, J.Brunet, C.Varenne, L.Mazet, A.Pauly, K.Wierzbowska \\ LASMEA (UMR 6602 CNRS), Université Blaise Pascal Clermont-Ferrand II, 24 avenue des Landais, \\ 63177 Aubière Cedex, France \\ Email: Iberry@univ-bpclermont.fr
}

\begin{abstract}
This paper deals with the influence of technological process steps on electrical and metrological parameters of $\mathrm{NO}_{2}$ gas sensors. The $\mathrm{NO}_{2}$ gas sensors are based on thin $\mathrm{n}-\mathrm{InP}$ epitaxial layers. The $\mathrm{NO}_{2}$ gas action makes the resistance of the device, measured in parallel to the surface between ohmic contacts, increase. It is demonstrated that the methodology of fabrication modifies the geometrical and physical parameters of ohmic contacts and the reproducibility of the devices. The impact on the gas sensors in response to $\mathrm{NO}_{2}$ is also discussed.
\end{abstract}

\section{Keywords}

gas sensor, InP, ohmic contacts, Nitrogen dioxide

\section{INTRODUCTION}

In view of the pollutants consequences on human health, the detection of the presence and the measurement of toxic gases (such as $\mathrm{NO}_{2}, \mathrm{O}_{3} \ldots$ ) have become essential for environmental protection. In recent years, the concentration of $\mathrm{NO}_{x}$ gases $\left(\mathrm{NO}\right.$ and $\left.\mathrm{NO}_{2}\right)$ in atmosphere has increased with increase in traffic and the number of buildings. Nitrogen oxides cause lung irritations, decrease the fixation of oxygen molecules on red blood cells, increase the susceptibility to infections, contribute to acid rains and play an important role in the formation of ozone in the lower atmosphere [1].

In air quality monitoring, epitaxial InP based sensors have demonstrated their oxidizing gases $\left(\mathrm{NO}_{2}\right.$, $\mathrm{O}_{2}, \mathrm{O}_{3}$ ) detection efficiency [1, 2]. According to previous laboratory experiments [3, 4], the InP based resistive gas sensor is sensitive to nitrogen dioxide. The resistance of $\mathrm{n}-\mathrm{InP}$ epitaxial layers, measured parallel to the surface, increases in the presence of $\mathrm{NO}_{2}$. The contacts used with the external circuit are ohmic, and the action of the gases is restricted to the surface between these contacts [5]. The devices have demonstrated an interesting response and a good lifetime. After several gas tests, the reproducibility of the response for one sensor has been validated. However, with the technological process developed to realize ohmic contacts [1], it was impossible to control the dimensions of the contacts, inducing problems of reproducibility between different samples.

Firstly, the technological process developed to improve the lack of reproducibility between different samples of $\operatorname{InP}$ based resistive gas sensors is presented.

Afterwards, the influence on ohmic contact resistance is studied.

In the end, the impact of the technological process on the gas sensors' response to $\mathrm{NO}_{2}$ is discussed. Based on two different technological processes, two different gas sensor samples are realised. The sensitivity, the stability and the influence of operating temperature between the two samples are discussed.

\section{EXPERIMENTS}

\subsection{SENSITIVE LAYER}

III-V semiconductor sensor is based on a thin n-type InP epitaxial layer, grown by molecular beam epitaxy on a semi-insulating Fe compensated InP substrate. The dimension of the $\mathrm{n}$-InP epitaxial layer is $9 \mathrm{~mm} \times 18 \mathrm{~mm}$, the thickness of the n-type layer is $200 \mathrm{~nm}$ and its doping level is $N_{D}=2.10^{16} \mathrm{~cm}^{-3}$.

In order to measure the resistance of the sensitive layer, ohmic contacts are made.

A particular process was defined to improve the reproducibility of ohmic contacts. Au/Ge/Au ohmic contacts were deposited on InP epitaxial layer by thermal evaporation under vacuum through a stainless steel mask (Fig. 1). 
Ohmic contacts with a thickness of $1450 \AA$ were made by sequential deposition of Au and Ge under a pressure of $10^{-7}$ Torr (Fig. 2). The first two layers were evaporated with a slow rate of $1 \AA . s^{-1}$ to optimize the homogeneity of the layers. Then, the last layer of Au was evaporated with a rate of 2-3 $A . s^{-1}$. Finally, the ohmic contacts were submitted to an annealing process under controlled and optimized conditions. The following annealing sequences in $\mathrm{H}_{2}\left(200^{\circ} \mathrm{C}\right.$ for $3 \mathrm{mn}, 250^{\circ} \mathrm{C}$ for $1 \mathrm{mn}$ and $300^{\circ} \mathrm{C}$ for 10s) have been performed for all ohmic contacts. The first annealing homogenized the contacts. The two last annealing formed a thin $\mathrm{n}^{+}-\mathrm{InP}$ layer at the metal/InP interface, leading to electrically good quality contacts.

\subsection{SENSOR DEVICE}

To investigate the influence of ohmic contacts on sensor samples reproducibility, stability and sensitivity, two different structures (Fig. 1) were realised.

The sample with 8 ohmic contacts was cleaved in two equal dimension samples with 4 ohmic contacts (the dimension of each sample is $9 \mathrm{~mm} \times 9 \mathrm{~mm}$ ). In first structure (called S1), Au wires $(0.38 \mu \mathrm{m}$ diameter) were bonded onto $\mathrm{Au} / \mathrm{Ge} / \mathrm{Au}$ ohmic contacts. In the second structure (called S2), the same wires were used with tin balls along side them. Finally the tin balls were attached with silver paste onto $\mathrm{Au} / \mathrm{Ge} / \mathrm{Au}$ ohmic contacts.

Finally, S1 and S2 were joined, with silver paste, to an alumina substrate fitted with a screen-printed Pt resistor on its back side, allowing heating and temperature control (Fig. 3).

\section{3. $\mathrm{NO}_{2}$ TEST EXPERIMENTS}

For $\mathrm{NO}_{2}$ test experiments, the structures were mounted together in the same stainless steel cylindrical cell. Measurements were made by recording the resistance variations of the $n$-type InP. The operating temperature was varied between $80^{\circ} \mathrm{C}$ and $140^{\circ} \mathrm{C}$. During laboratory experiments, the $\left(\mathrm{NO}_{2}\right)$ test gas was diluted in dry pure air and its concentration was monitored by mass flow controllers. The total gas flow was kept constant at $50 \mathrm{l} / \mathrm{h}$.

For every gas test experiments, the InP sensors were maintained in darkness because of their light sensitivity, and the sensors' recorded signal was the resistance of the layer.

Data was recorded every 1 min by a Keithley digital multimeter and then compared with nitrogen dioxide concentrations delivered by a dual chamber chemiluminescent nitrogen oxides monitor (model AC32M, Environnement S.A.).

\section{INFLUENCE ON OHMIC CONTACT RESISTANCE}

For S1 and S2 structures, we present measurements on contact resistances of $\mathrm{Au} / \mathrm{Ge} / \mathrm{Au}$ ohmic contacts to n-type $\ln P$.

The results are discussed to evaluate the dependence of contact resistances on:

- the surface and the geometry of the sensitive layer,

- the process used to attach Au wires onto Au/Ge/Au ohmic contacts.

To estimate the impact of the surface and the geometry of the sensitive layer, the resistance between two contacts was measured for a S1 type structure. Each contact was numbered as described in figure 4 .

Table1 summarizes the value of the linear electrical resistance measured between contacts 1 and 3 after three successive splittings described in the figure 5 . The linear distance between contacts 1 and 3 was measured equal to $3.8 \mathrm{~mm}$.

The linear electrical resistance decreases with the reduction of the surface layer. The splitting concentrated on the reduction of the sample perimeter gives information of the repartition of the electric field lines between two contacts. The impact of the surface perimeter on the electrical resistance between two contacts demonstrates the non-linear distribution of the electric field lines.

Furthermore, the imperfect linearity of the variation of the linear electrical resistance with the sample surface is probably linked to the non uniform doping level on the whole surface. 
In another experiment, for S1 and S2 structures (Fig. 1), the variation of contact resistance was evaluated before and after wire attachment bonding, and before and after the addition of tin ball (Table2). The contact resistances were defined applying the Van Der Pauw method. The difference in contact resistance between S1 and S2 structures is linked to the geometry of the sensitive layer.

For S1 structure, contact resistance is approximately stable before and after wire attachment. For S2 structure, the contact resistance measured after tin balls' addition is smaller than one measured before. Therefore, the addition of tin ball improves the quality of ohmic contact. However, the reproducibility of $\mathrm{S} 2$ structure is not systematically guaranteed.

In $\mathrm{NO}_{2}$ test experiments, how has this difference of the contact resistance influenced on the sensor behaviour of $\mathrm{S} 1$ and $\mathrm{S} 2$ ?

\section{INFLUENCE ON NO${ }_{2}$ TEST EXPERIMENTS}

Amongst all the tested gases $\left(\mathrm{CO}, \mathrm{O}_{2}, \mathrm{NO}_{2}, \mathrm{CH}_{4}, \mathrm{Cl}_{2}, \mathrm{NH}_{3}\right)$, it is noted that nitrogen dioxide had the strongest action on the sensor output. According to our previous laboratory experiments, when an InP layer is exposed to an oxidizing gas such as $\mathrm{NO}_{2}$ (electron acceptor), gaseous molecules get adsorbed on the InP surface; some of them become negatively ionized $\left(\mathrm{NO}_{2}{ }^{-}\right)$by chemisorption. The formation of these ions induces a repulsive electric field for the majority carriers of $n$-type $\ln P$, creating a depleted zone just below the surface. Consequently, the effective cross-section for the current flow between the contacts is reduced and the resistance increases $[3,4,5]$.

It is well known that increasing the working temperature of a semi-conducting gas sensor improves the speed of adsorption and desorption and, consequently, the response and recovery times [6].

We have studied the effect that temperature has on the response of S1 and S2 structures to different concentrations of $\mathrm{NO}_{2}: 40 \mathrm{ppb}, 60 \mathrm{ppb}, 80 \mathrm{ppb}$ and $100 \mathrm{ppb}$ of $\mathrm{NO}_{2}$ diluted in dry pure air.

For S1 and S2 structures, metrological characteristics were estimated:

- the response time : time to reach $90 \%$ of the final value under the $\mathrm{NO}_{2}$ gas submission,

- the recovery time : time to fall below $10 \%$ of the maximum response after the $\mathrm{NO}_{2}$ gas submission,

- the sensitivity or relative variation of the resistance.

With temperature, the three parameters are nearly same (Table 3). These three parameters decrease with the operating temperature.

Therefore, the difference of the contact resistance between S1 and S2 has no influence on their sensor behaviour. The samples are reproducible because the technological process allows controlling the distance between ohmic contacts and their geometry. This result consolidates the assumption according to which the gas contact interaction can be rejected [3]. However, after several submissions to $\mathrm{NO}_{2}$, it could be interesting to evaluate the stability of ohmic contacts between S1 and S2.

Moreover, the stability of $R_{0}$ is optimal at $100^{\circ} \mathrm{C}$. Below $100^{\circ} \mathrm{C}$, the long recovery time leading to an unstable baseline is problematic for sensor applications. Above $100^{\circ} \mathrm{C}, \mathrm{R}_{\mathrm{o}}$ continuously decreases (Fig. 6).

After one week of $\mathrm{InP}$ submission to $\mathrm{NO}_{2}$ at $140^{\circ} \mathrm{C}$, a new test was realised at $100^{\circ} \mathrm{C}$. $\mathrm{R}_{0}$ decreased before and after the experiments at $140^{\circ} \mathrm{C}$ (Table 4). It could be linked to an irreversible effect.

However, the response to $\mathrm{NO}_{2}$ is nearly the same before and after the experiments at $140^{\circ} \mathrm{C}$ (Table 4). This result was observed all along the period of tests despite the continuous decrease of $R_{0}$. It is well known that freshly grown InP layers are covered with a very thin oxide layer $(\approx 2 \mathrm{~nm})$ as soon as they are exposed to ambient atmosphere, and species such as $\ln _{2} \mathrm{O}_{3}$ and $\mathrm{P}_{2} \mathrm{O}_{5}$ have been identified $[7,8]$. This chemically stable layer could induce a permanent depleted zone. In this case, the action of $\mathrm{NO}_{2}$ increases this zone. Resistance varies in the same way as before. However, an influence of the temperature on the stability of surface oxygen species like $\ln _{2} \mathrm{O}_{3}$ or $\mathrm{P}_{2} \mathrm{O}_{5}$ could explain the effect of the temperature on the gas sensor response. At $140^{\circ} \mathrm{C}$, the continuous decrease of $R_{0}$ could be linked to a rearrangement of surface oxygen species not sufficiently stabilised.

The process involved, reversible or irreversible could depend on different time constants. It could be associated with physicochemical parameters of the initial oxide layer which depend on experimental conditions [9]. 
Recently, XPS spectra (X-ray Photoelectron Spectra) of InP surfaces, before and after $\mathrm{NO}_{2}$ submission, as well as theoretical calculations on surface states (or near surface region at $\operatorname{InP}$ surfaces) were developed in the laboratory [10]. The results have demonstrated the development of a complex InP related oxide layer at the surface, which gives rise to the high density of surface states. The surface state and depletion layer influences strongly on the layer sensitivity to ion adsorption. This role of the surface oxide layer on the layer sensitivity could explain the observed $R_{0}$ instability with operating temperature. It could be linked to the instability or rearrangement of the surface oxide layer with temperature.

\section{CONCLUSION}

The technological process developed to optimize the reproducibility of $\ln P$ sensor samples is based on two principles:

- the control of the distance between ohmic contacts and their geometry,

- the wire bonding technology is optimal for the reproducibility. Even if tin ball attachment improves the quality of ohmic contact, the long term stability of the attachment is not guaranteed in test conditions with gases. An experimental study on the long term stability between the two structures $\mathrm{S} 1$ and $\mathrm{S} 2$ is needed.

Based on four months experiments, $\mathrm{NO}_{2}$ test experiments reject a gas contact interaction. The study concerning the influence of the operating temperature on the $\operatorname{InP}$ response to $\mathrm{NO}_{2}$ is coherent with reversible or irreversible process depending on different time constants, which could be associated to the variation of physicochemical parameters of the initial oxide layer with experimental conditions.

\section{References}

[1]: L.Talazac, J.Brunet, V.Battut, J.P.Blanc, A.Pauly, J.P.Germain, S.Pellier, C.Soulier, Air quality evaluation by monolithic InP-based resistive sensors, Sensors and Actuators B76, 2001, 258-264

[2]: L.Talazac, F.Barbarin, C.Varenne, L.Mazet, S.Pellier, C.Soulier, Gas sensing properties of pseudo-schottky diodes on p-type indium phosphide substrates : application to $\mathrm{O}_{3}$ and $\mathrm{NO}_{2}$ monitoring in urban ambient air, Sensors and Actuators B83, 2002, 149-159.

[3]: V.Battut, J.P.Blanc, C.Maleysson, Gas sensitivity of $\operatorname{InP}$ epitaxial thin layers, Sensors and Actuators B44, 1997, 503-506.

[4]: L.Talazac, J.P.Blanc, V.Battut, F.Mollot, $\mathrm{NO}_{2}$ sensitivity of thin n-type InP epitaxial layers, Electron. Technol. 33, 2000, 213-216

[5]: V. Battut, J. P. Blanc, E. Goumet, V. Soulière and Y. Monteil, $\mathrm{NO}_{2}$ sensor based on InP epitaxial thin layers, Thin solid films, Volume 348, 1999, 266-272.

[6]: M.Dugay, C.Maleysson, Thin layers of poly(fluoroaluminium-phtalocyanine), Synthetic Metals, 21, 1987, 255-260.

[7]: S.Selci, A.Cricenti, A.C.Felici L.Ferrari, C.Goletti, G.Chiarotti, Oxygen chemisorption on cleaved InP (110) surfaces studied with surface differential reflectivity, Phys.rev., B43 - 8, 1991, 6757-6759

[8]: D.X.Dai, F.R.Zhu, Auger-electron spectroscopy, electron-energy-loss spectroscopy, and x-ray photoemission spectroscopy studies of oxygen adsorption on the InP (111)-(1×1) surface, Phys.Rev., B43 - 6, 1991, 4803-4808.

[9]: A.Gurlo, N.Bârsan, M.Ivanovskaya, U.Weimar, W.Göpel, $\mathrm{NO}_{2}$ detection by a resistive device based on n-InP epitaxial layers, Sensors and Actuators B: Chemical, Volume 47, Issues 1-3, 1998, 9299

[10]: K.Wierzbowska, B.Adamowicz, L.Mazet, J.Brunet, A.Pauly, L.Bideux, C.Varenne, L.Berry, JP.Germain, High-sensitivity $\mathrm{NO}_{2}$ sensor based on n-type $\operatorname{InP}$ epitaxial layers, Optica Applicata, Vol.XXXV, №3, 2005. 


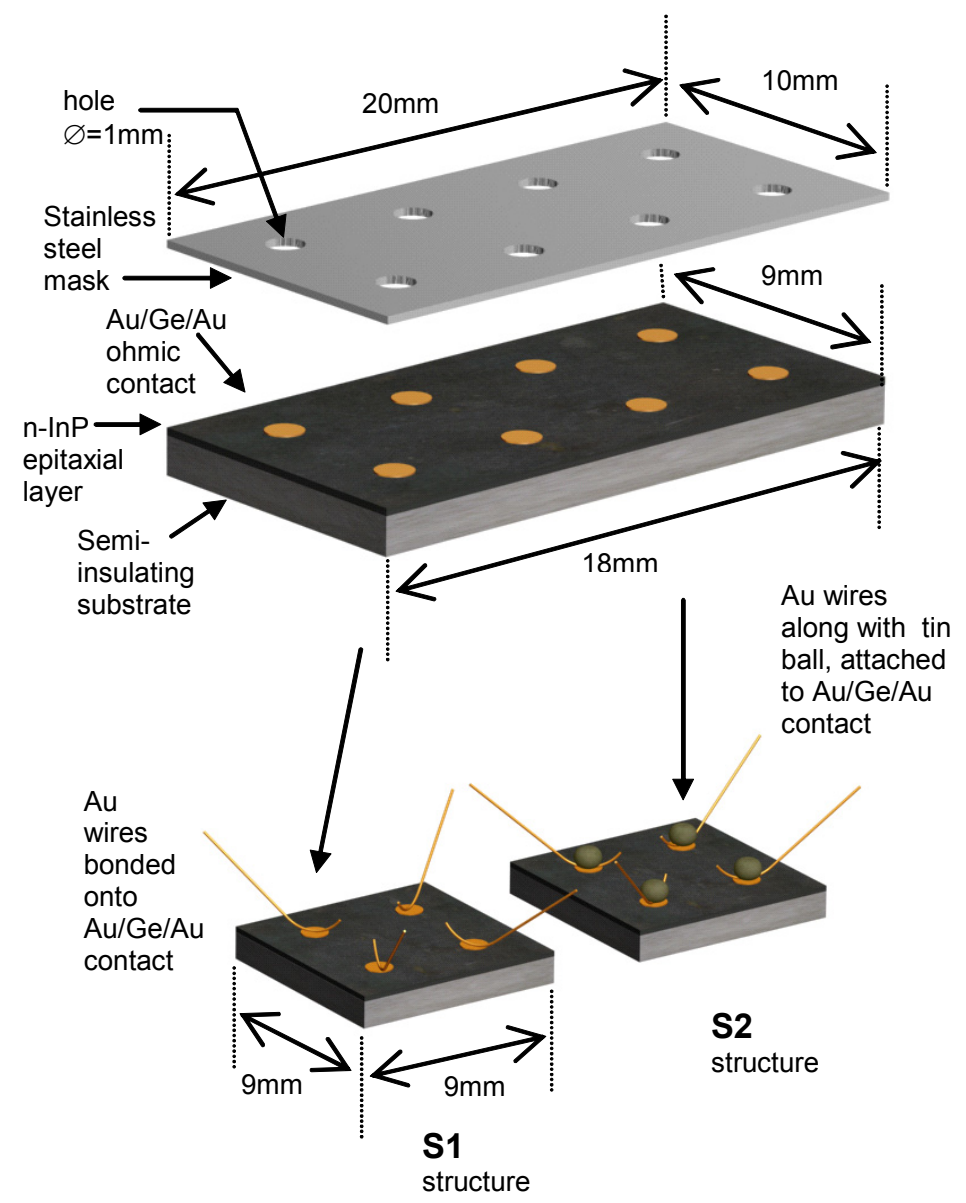

Fig. 1 : Au/Ge/Au ohmic contact thermally evaporated on n-type InP epitaxial layer (200nm) 


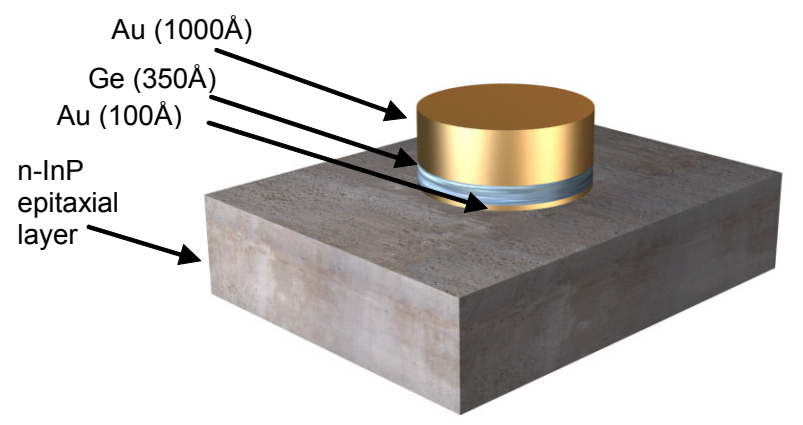

Fig. 2 : Au/Ge/Au metallization scheme 


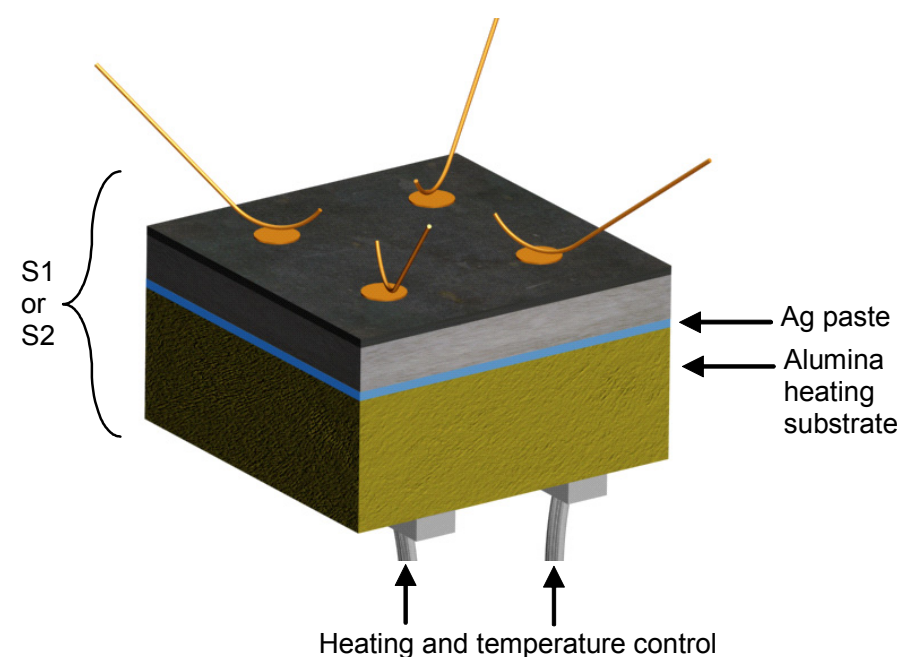

Fig. 3 : n-type InP based sensor device 


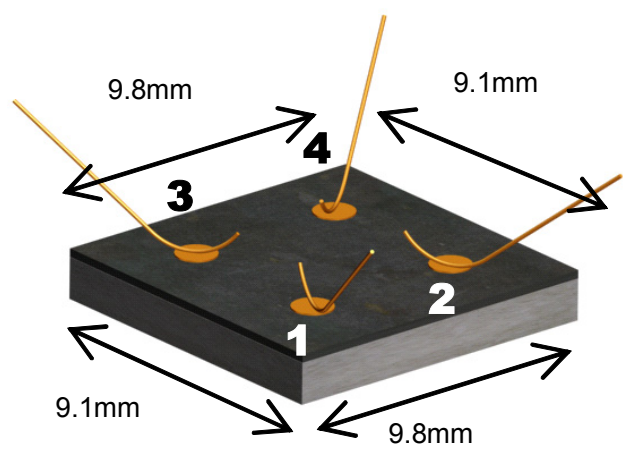

Fig. 4 : geometrical parameters of the sensitive layer and ohmic contacts 

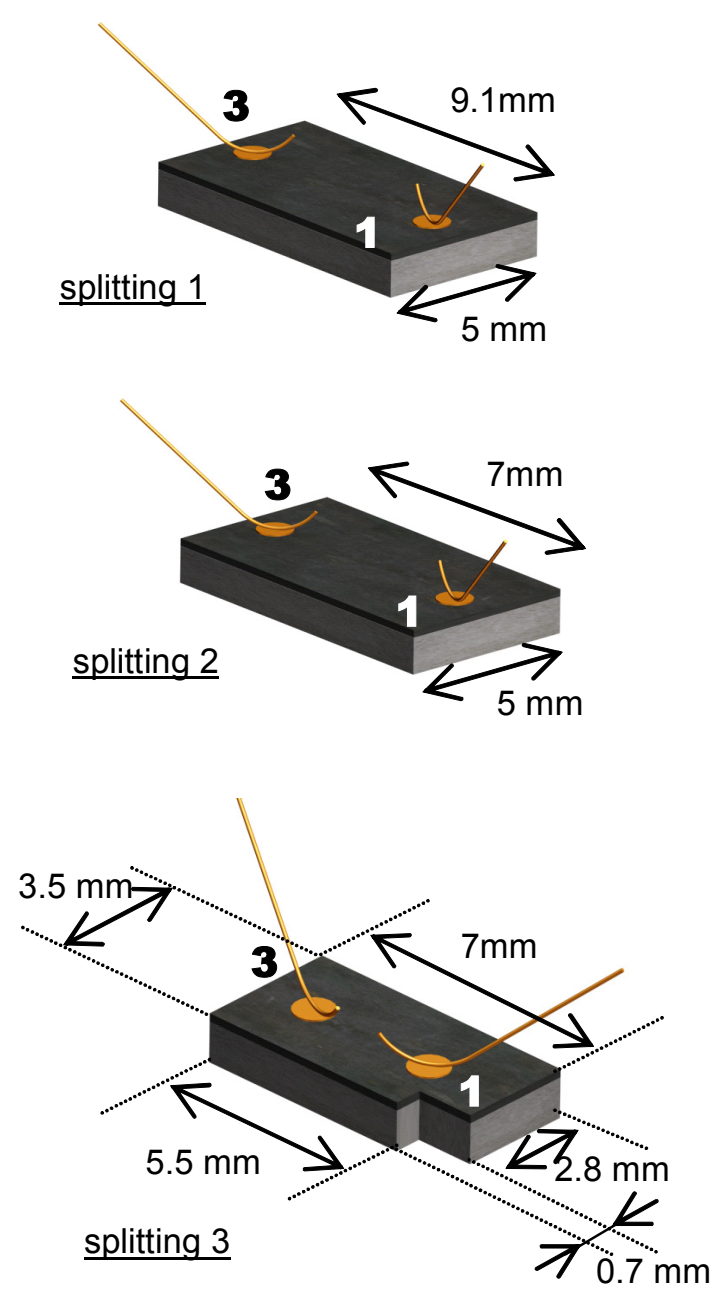

Fig.5 : details of the successive splitting 


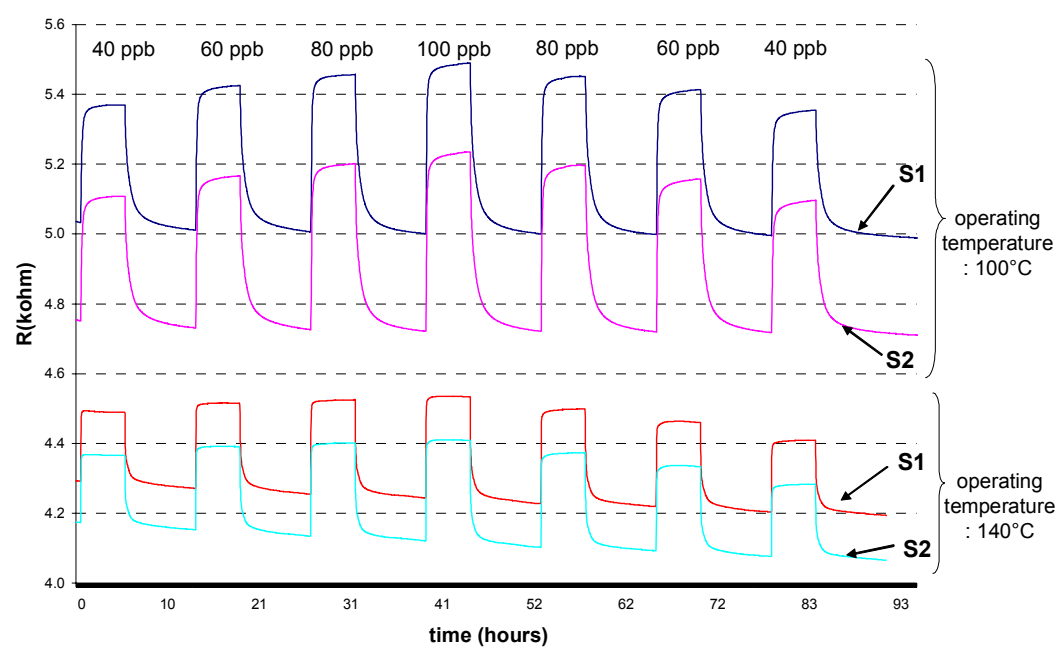

Fig 6. : $\mathrm{NO}_{2}$ test experiments 


\begin{tabular}{|c|c|c|}
\hline step & $\begin{array}{c}\text { Linear electrical } \\
\text { resistance }(\mathrm{k} \Omega\end{array}$ & $\begin{array}{c}\text { sensitive layer } \\
\text { surface }\left(\mathrm{mm}^{2}\right)\end{array}$ \\
\hline Splitting 1 & $\mathrm{R}_{13}=8.9$ & 45.5 \\
\hline Splitting 2 & $\mathrm{R}_{13}=10.8$ & 35.0 \\
\hline Splitting 3 & $\mathrm{R}_{13}=11.5$ & 23.5 \\
\hline
\end{tabular}

Table 1. linear electrical resistances measurements 


\begin{tabular}{|c|c|c|c|c|}
\hline \multirow{2}{*}{ Contact resistance } & \multicolumn{2}{|c|}{ S1 structure } & \multicolumn{2}{c|}{ S2 structure } \\
\cline { 2 - 5 } & Before wire bonding & After wire bonding & Before tin ball attachment & After tin ball attachment \\
\hline $\operatorname{Rc} 1(\Omega)$ & 1199 & 1191 & 1060 & 910 \\
\hline $\operatorname{Rc} 2(\Omega)$ & 1091 & 1083 & 935 & 920 \\
\hline $\operatorname{Rc} 3(\Omega)$ & 1160 & 1148 & 1105 & 1053 \\
\hline $\operatorname{Rc} 4(\Omega)$ & 1211 & 1202 & 1243 & 912 \\
\hline
\end{tabular}

Table 2. Influence of ohmic contacts 


\begin{tabular}{|c|c|c|c|c|c|}
\hline $\begin{array}{c}\text { for } \\
100 p p b \\
N_{2}\end{array}$ & & $80^{\circ} \mathrm{C}$ & $100^{\circ} \mathrm{C}$ & $120^{\circ} \mathrm{C}$ & $140^{\circ} \mathrm{C}$ \\
\hline \multirow{2}{*}{$\begin{array}{l}\text { Response } \\
\text { time }(m n)\end{array}$} & S1 & 21 & 19 & 9 & 5 \\
\hline & S2 & 22 & 21 & 10 & 5 \\
\hline \multirow{2}{*}{$\begin{array}{l}\text { Recovery } \\
\text { time }(\mathrm{h})\end{array}$} & S1 & $3 \mathrm{~h} 04 \mathrm{mn}$ & $2 \mathrm{~h} 03 \mathrm{mn}$ & $1 \mathrm{~h} 37 \mathrm{mn}$ & $1 \mathrm{~h} 03 \mathrm{mn}$ \\
\hline & S2 & 3h02mn & $2 \mathrm{~h} 15 \mathrm{mn}$ & 1h35mn & 1h04mn \\
\hline \multirow{2}{*}{$\begin{array}{l}\text { Sensitivity } \\
\left(\mathrm{R}-\mathrm{R}_{\mathrm{o}}\right) / \mathrm{R}_{\mathrm{o}}\end{array}$} & S1 & 0.125 & 0.098 & 0.081 & 0.067 \\
\hline & S2 & 0.143 & 0.108 & 0.089 & 0.070 \\
\hline
\end{tabular}

Table 3. Influence of operating temperature 


\begin{tabular}{|c|c|c|c|c|}
\hline for $\begin{array}{c}100 \mathrm{ppb} \\
\mathrm{NO}_{2}\end{array}$ & & $100^{\circ} \mathrm{C}$ & $140^{\circ} \mathrm{C}$ & $100^{\circ} \mathrm{C}$ \\
\hline $\begin{array}{c}\text { Response } \\
\text { time }(\mathrm{mn})\end{array}$ & $\mathrm{S} 1$ & 19 & 5 & 18 \\
\cline { 2 - 5 } $\begin{array}{c}\text { Recovery } \\
\text { time }(\mathrm{h})\end{array}$ & $\mathrm{S} 1$ & $2 \mathrm{~h} 03 \mathrm{mn}$ & $1 \mathrm{~h} 03 \mathrm{mn}$ & $2 \mathrm{~h} 07 \mathrm{mn}$ \\
\cline { 2 - 5 } & $\mathrm{S} 2$ & $2 \mathrm{~h} 15 \mathrm{mn}$ & $1 \mathrm{~h} 04 \mathrm{mn}$ & $2 \mathrm{~h} 17 \mathrm{mn}$ \\
\hline $\begin{array}{c}\text { Sensitivity } \\
\left(\mathrm{R}-\mathrm{R}_{\mathrm{o}}\right) / \mathrm{R}_{\circ}\end{array}$ & $\mathrm{S} 1$ & 0.098 & 0.067 & 0.094 \\
\cline { 2 - 5 } & $\mathrm{S} 2$ & 0.108 & 0.070 & 0.099 \\
\hline $\mathrm{R}_{\mathrm{o}}(\mathrm{k} \Omega)$ & $\mathrm{S} 1$ & 5.0 & 4.0 & 4.4 \\
\cline { 2 - 5 } & $\mathrm{S} 2$ & 4.75 & 3.9 & 4.25 \\
\hline
\end{tabular}

Table 4. Influence of experiments at $140^{\circ} \mathrm{C}$ 